\title{
Pollen-based paleoclimate reconstructions of North-Eastern Bulgaria during the last 7000 years using modern analog technique (MAT)
}

\section{Палеоклиматични реконструкции в района на Североизточна България през последните 7000 години по данни от спорово-поленовия анализ и метода на съвременните аналози}

\author{
Stoyan Vergiev ${ }^{1}$, Mariana Filipova-Marinova ${ }^{2}$ \\ Стоян Вергиев ${ }^{1}$ Мариана Филипова-Маринова ${ }^{2}$ \\ ${ }^{1}$ Department of Ecology and Environmental Protection, Technical University of Varna, 1 Studentska St, 9010 Varna, Bulgaria; \\ E-mail: stvergiev@gmail.com \\ ${ }^{2}$ Museum of Natural History - Varna, 41 Maria Louisa Blvd., 9000 Varna, Bulgaria; E-mail: marianafilipova@yahoo.com
}

\begin{abstract}
The aim of the present study is to reconstruct the palaeoclimate variables in North-Eastern Bulgaria during the last 7000 years, based on the pollen analysis from 2 lacustrine cores and using modern analogue technique (MAT). Pollen data were used for the reconstruction of four parameters: the average annual temperature, the average temperature of the warm and cold half-year and the average annual precipitation.
\end{abstract}

Keywords: pollen, palaeoclimate reconstructions, modern analogue technique, North-Eastern Bulgaria.

\section{Въведение}

Класическите палеоклиматични реконструкции се основават на качествени интерпретации на фосилните поленови спектри, получени при спорово-поленовия анализ (Guiot, 1990; Vergiev, Filipova-Marinova, 2019). Необходимостта от точни количествени данни за палеоклиматите налага прилагането на количествени математически модели, от които най-голямо приложение за кватернерни седименти намира Методът на съвременните аналози (MCA) (Overpeck et al., 1985). Този метод се основава на събирането на съвременни повърхностни поленови проби и на сравнението на наличието и процентното участие на поленови типове в тях със съвременни климатични данни, като по този начин се установява зависимостта полен-климат (Vergiev, Filipova-Marinova, 2019). Климатичните променливи, свързани с най-сходната съвременна проба, могат да бъдат асоциирани към времето и мястото на фосилната проба, която се реконструира в рамките на даден географски район. По този начин, за разлика от класическите качествени интерпретации на поленовите спектри, чрез МСА може да се извърши количествена оценка и да се изведат точни данни за параметрите на палеоклиматите.
Целта на настоящото изследване е, на базата на съвременните климатични данни, да се възстановят определени климатични променливи (средногодишна температура, средна температура на студеното полугодие, средна температура на топлото полугодие и средногодишна сума на валежите) за Североизточна България през последните 7000 години чрез спорово-поленов анализ и с използването на метода на съвременните аналози.

\section{Материал и методи}

Анализирано е съдържанието на спори и полен в седиментите от два сонджа. Сондаж C-2 е прокаран в близост до северния бряг на Варненското езеро, при дълбочина на водния слой $7 \mathrm{~m}$. Изследваната дължина на сондажания разрез е $660 \mathrm{~cm}$. Сондаж Sh-Ez 2 е прокаран в северната част на Езерецкото езеро, при дълбочина на водния слой $30 \mathrm{~cm}$. Дължината на сондажа е $705 \mathrm{~cm}$.

На база на извършеното AMS радиовъглеродно датиране на 7 избрани проби от сондаж C-2 (Filipova-Marinova et al., 2013) и 8 проби от сондаж Sh-Ez 2 (Filipova, 1985), бяха създадени геохронологични (възрастови) модели, чрез които се осъществи корелацията на сондажите. 
За извършване на реконструкцията на климатичните променливи беше използван Методьт на съвременните аналози (Overpeck et al., 1985; Guiot, 1990). Статистическата обработка на данните беше извършена със софтуерния продукт Polygon 2.3 (Nakagawa et al., 2002).

В настоящото изследване е използван съвременен калибрационен сет от Българското Черноморско крайбрежие, съдържащ данни за 394 съвременни поленови спектъра и съвременни климатични данни (Vergiev, 2014, 2019; Vergiev, Filipova-Marinova, 2019). Въз основа на факторен анализ на променливите и процентното участие на всеки тип в съвременните спектри се доказа надеждността на данните и възможността им да бъдат включени при сравнението с фосилните поленови спектри (Vergiev, FilipovaMarinova, 2019).

\section{Резулатати и обсъждане}

Извършена е реконструкция на климатичните параметри, като са използвани минимум 8 съвременни аналози за всяка фосилна проба. Стойностите на средногодишната температура (СГТ), средната температура на студеното полугодие (СТСП), средната температура на топлото полугодие (СТТП) и средногодишната сума на валежите (СГСВ) са използвани за изчертаване на климатични криви (фиг. 1).

На база на реконструираните данни могат да бъдат отделени 3 времеви интервала. През пър-

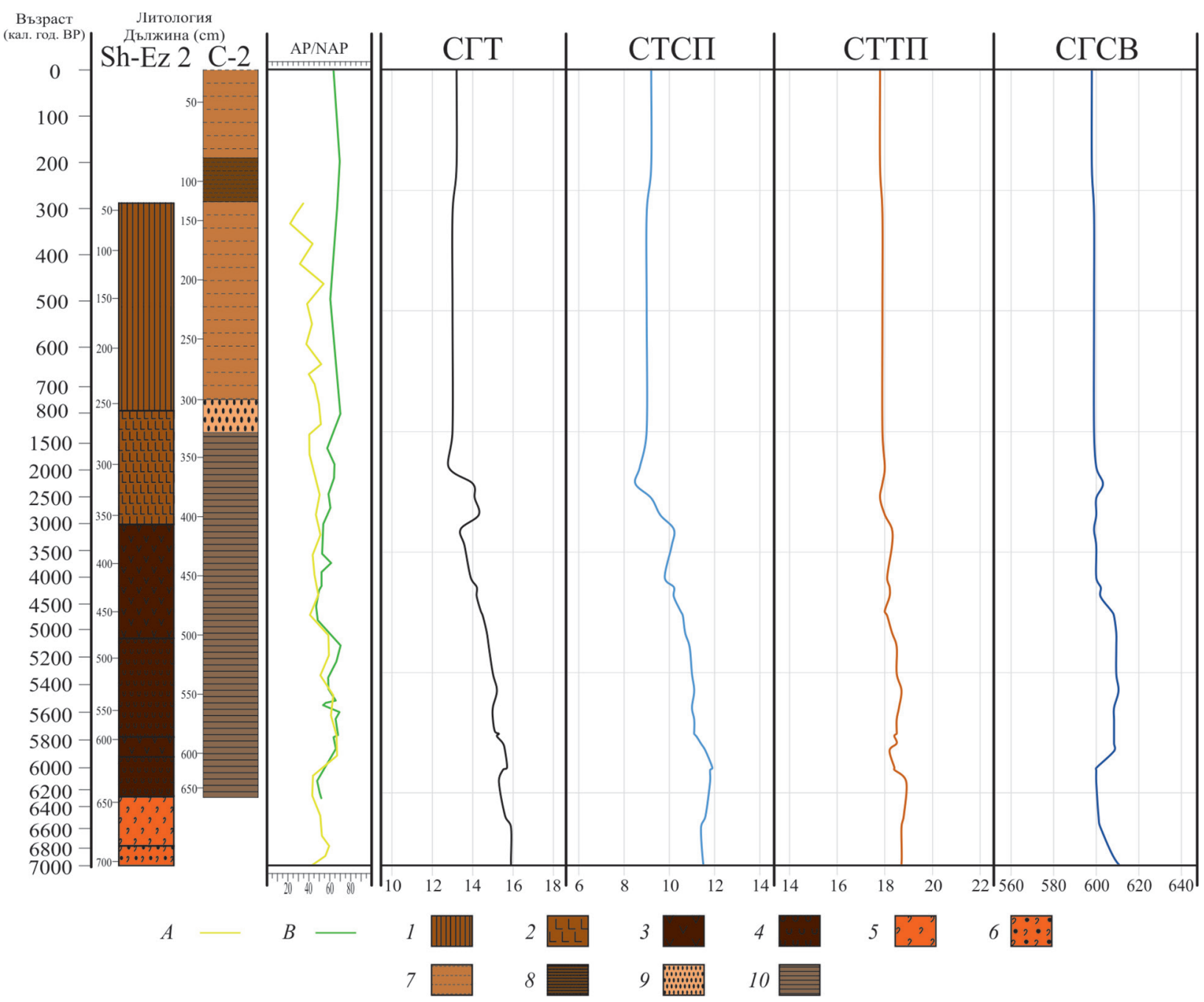

Фиг. 1. Реконструкция на палеоклиматичните променливи: СГТ - средногодишна температура $\left({ }^{\circ} \mathrm{C}\right)$; СТСП - средна температура на студеното полугодие $\left({ }^{\circ} \mathrm{C}\right)$; СТТП - средна температура на топлото полугодие $\left({ }^{\circ} \mathrm{C}\right)$; $\mathrm{C}$ СВ - средногодишна сума на валежите $\left(\mathrm{mm} / \mathrm{m}^{2}\right): A$ - дървесни и храстови таксони (АР \%), $B$ - тревисти таксони (NAP \%), 1 - тръстиков торф, 2 - торф и молюски, 3 - молюски и гития, 4 - гития и молюски, 5 - молюсков детритус, 6 - пясък и молюски, 7 - бежовосиви глини, 8 - сиви глини, 9 - песъчливо-глинест слой, 10 - ламинирани глини 
вия интервал (7000-5000 кал. год. ВР) са отчетени най-високи стойности на термалните параметри, което съвпада с холоценския климатичен оптимум. Реконструкцията на осреднената СГТ показва стойност $15,2 \pm 0,5{ }^{\circ} \mathrm{C}$. В този интервал е отбелязан и абсолютният максимум за изследвания период $-15,9 \pm 0,8{ }^{\circ} \mathrm{C}$. Валежите са относително високи, но са под предполагаемите средни стойности за атлантическия период. Закономерно,

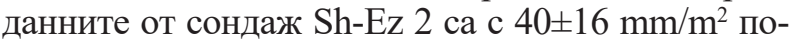
ниски от реконструираните данни от сондаж C-2.

Кривите на термалните параметри в интервала 5000-3000 кал. год. ВР показват динамика и тенденция на намаление, като осреднените

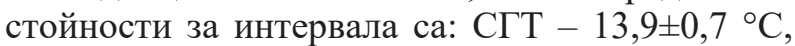
СТСП - 9, $8 \pm 0,5{ }^{\circ} \mathrm{C}$, СТТП $-17,9 \pm 0,5{ }^{\circ} \mathrm{C}$. СГСВ има средна стойност $589 \pm 22 \mathrm{~mm} / \mathrm{m}^{2}$, като се отбелязва трайна тенденция на намаление.

Последният времеви интервал (3000 кал. год. BP) се характеризира с еднородност на климатичните параметри, които показват почти идентични стойности. Усреднените стойности за интервала са: СГТ - $12,9 \pm 0,6{ }^{\circ} \mathrm{C}, \mathrm{CTCП}-8,8 \pm 0,6{ }^{\circ} \mathrm{C}$, СТТП - $17,6 \pm 0,4{ }^{\circ} \mathrm{C}$. СГСВ за този интервал е $548 \pm 40 \mathrm{~mm} / \mathrm{m}^{2}$.

\section{Заключение}

На базата на извършения спорово-поленов анализ на проби от двата езерни сондажа от Североизточна България бяха отделени 3 климатични интервала, за които бяха реконструирани климатичните променливи: средногодишна температура, средна температура на студеното полугодие, средна температура на топлото полугодие и средногодишна сума на валежите през последните 7000 години. През първия интервал (70005000 кал. год. ВР) са отчетени най-високи стойности на термалните параметри, което съвпада с холоценския климатичен оптимум. Валежите са относително високи, но са под предполагаемите средни стойности за атлантическия период.
Кривите на термалните параметри в интервала 5000-3000 кал. год. ВР показват динамика и тенденция на намаление. Последният времеви интервал (след 3000 кал. год. ВР) се характеризира с еднородност на климатичните параметри, които показват почти идентични стойности.

Благодарности: Част от научните изследвания, резултатите от които са представени в настоящата публикация, са извършени в рамките на присъщата на ТУ-Варна научноизследователска дейност, финансирана целево от държавния бюджет.

\section{Литература}

Filipova, M. 1985. Palaeoecological investigations of Lake Shabla-Ezeretz in North-Eastern Bulgaria. -Ecologia Mediterranea, 11, 1, 148-158.

Filipova-Marinova, M., D. Pavlov, S. Vergiev, V. Slavchev, L. Giosan. 2013. Palaeoecology and geoarchaeology of Varna Lake, Northeastern Bulgaria. - C. R. Acad. Bulg. Sci., 66, 3, 377-392.

Guiot, J. 1990. Methodology of the last climatic cycle reconstruction in France from pollen data. - Palaeogeogr., Palaeoclimatol., Palaeoecol., 80, 49-69.

Nakagawa, T., P. Tarasov, K. Nishidac, K. Gotanda, Y. Yasuda. 2002. Quantitative pollen-based climate reconstruction in central Japan: application to surface and Late Quaternary spectra. - Quaternary Sci. Rev., 21, 2099-2113.

Overpeck, J, T. Webb, C. Prentice. 1985. Quantitative interpretation of fossil pollen spectra: dissimilarity coefficients and the method of modern analogues. - Quaternary Res., 23, 87-108.

Vergiev, S. 2014. Palaeoecology and Geoarchaeology of Upper Pleistocene and Holocene sediments from the Black Sea Deep Water Zone and the Varna Lake. Unpublished $\mathrm{PhD}$ Thesis, M. Drinov Publish. House, BAS, 201 p. (in Bulgarian).

Vergiev, S. 2019. GIS-based modern pollen-climate calibration set from eastern Bulgaria for 2017. - SocioBrains, 54, 202-208 (in Bulgarian with English abstract).

Vergiev, S., M. Filipova-Marinova. 2019. GIS-based model for analysis of modern pollen-climate relationship. - In: Scientific Works of the Union of Scientists in Bulgaria-Plovdiv. Series C, Technics and Technologies, 18, 240-246 (in Bulgarian with English abstract). 